\title{
41.6 Gb/s RZ-DPSK to NRZ-DPSK Format Conversion in a Microring Resonator
}

Xiong, Meng; Ozolins, Oskars; Ding, Yunhong; Huang, Bo; An, Yi; Ou, Haiyan; Peucheret, Christophe; Zhang, Xinliang

Published in:

Proceedings of the 17th OptoElectronics and Communications Conference

Link to article, DOI:

10.1109/OECC.2012.6276682

Publication date:

2012

Link back to DTU Orbit

Citation (APA):

Xiong, M., Ozolins, O., Ding, Y., Huang, B., An, Y., Ou, H., Peucheret, C., \& Zhang, X. (2012). 41.6 Gb/s RZDPSK to NRZ-DPSK Format Conversion in a Microring Resonator. In Proceedings of the 17th OptoElectronics and Communications Conference (pp. 891-892 ). IEEE. https://doi.org/10.1109/OECC.2012.6276682

\section{General rights}

Copyright and moral rights for the publications made accessible in the public portal are retained by the authors and/or other copyright owners and it is a condition of accessing publications that users recognise and abide by the legal requirements associated with these rights.

- Users may download and print one copy of any publication from the public portal for the purpose of private study or research.

- You may not further distribute the material or use it for any profit-making activity or commercial gain

- You may freely distribute the URL identifying the publication in the public portal 


\title{
41.6 Gb/s RZ-DPSK to NRZ-DPSK Format Conversion in a Microring Resonator
}

\author{
Meng Xiong****, Oskars Ozolins*****, Yunhong Ding**, Bo Huang***, Yi An**, \\ Haiyan $\mathrm{Ou}^{* *}$, Christophe Peucheret**, and Xinliang Zhang* \\ * Wuhan National Laboratory for Optoelectronics, School of Optoelectronics Science and Engineering, Huazhong \\ University of Science and Technology, Wuhan, 430074, Hubei, People's Republic of China \\ ** Department of Photonics Engineering, Technical University of Denmark, 2800 Kgs. Lyngby, Denmark \\ *** Telecommunications Institute, Riga Technical University, LV-1048 Riga, Latvia \\ Email: menxi@fotonik.dtu.dk
}

\begin{abstract}
RZ-DPSK to NRZ-DPSK format conversion in a silicon microring resonator is demonstrated experimentally for the first time at $41.6 \mathrm{~Gb} / \mathrm{s}$. The converted signal eye diagrams and bit-error-rate measurements show the good performance of the scheme.
\end{abstract}

\section{INTRODUCTION}

All optical format conversion of return-to-zero (RZ) to non return-to-zero (NRZ) signals is a desired function to interface different parts of a future ubiquitous transparent optical network. Many schemes for on-off keying (OOK) conversion using active [1] or passive [2-4] operations have been demonstrated in the past years. Differential phase shift keying (DPSK) has received special attention over the past decade due to its improved receiver sensitivity with balanced detection and superior transmission properties. Recently, single [5] and multichannel [6] RZ-DPSK to NRZ-DPSK conversion have been demonstrated using a delay interferometer (DI) with half bit delay. Such devices may however be bulky.

Recently, silicon photonics has received increased interest due to its compact size and compatibility with microelectronics fabrication processes. Silicon microring resonators are versatile ultra-compact devices enabling the implementation of numerous functionalities. In this paper, we propose and demonstrate for the first time a novel scheme for RZ-DPSK to NRZ-DPSK format conversion with little power penalty at $41.6 \mathrm{~Gb} / \mathrm{s}$ based on a well optimized silicon microring resonator (MRR).

\section{OPERATION PRINCIPLE}

The principle of the format conversion is the linear filtering process at the through port of the MRR. By suppressing spectral components using a MRR with free spectral range (FSR) equal to twice the signal bit rate, RZ-DPSK can be converted to NRZ-DPSK, at the expense of some amplitude ripple, as shown in Fig. 1(c). The ripple can be efficiently reduced thanks to an additional optical bandpass filter (OBPF). The method

This work was supported by the National Basic Research Program of China (Grant No. 2011CB301704) and the National Natural Science Foundation of China (Grant No. 61007042). Meng Xiong thanks the support of the Chinese Scholar Council (CSC). Support of the European Social Fund for the project "Implementation of doctoral studies at Riga Technical University" is acknowledged. has already been successfully demonstrated for RZ-OOK to NRZ-OOK conversion [4]. However, its use for DPSK format conversion has never been reported so far.

The amplitude ripple of the converted NRZ-DPSK and the $\mathrm{Q}$ value of the demodulated signal depend on the power coupling coefficient of the MRR and the 3-dB bandwidth of the OBPF, as shown in Fig. 1(a) and (b). For good conversion performance, low ripple and high $\mathrm{Q}$ values are required. Those quantities have been simulated as a function of the MRR power coupling coefficient for a fixed OBPF bandwidth of $125 \mathrm{GHz}$. As can be seen in Fig. 1(e), when the power coupling coefficient increases, the ripple decreases while the $\mathrm{Q}$ value becomes larger. An MRR with power coupling coefficient of 0.9 results in a ripple lower than 0.5 and $Q$ value higher than 30 .

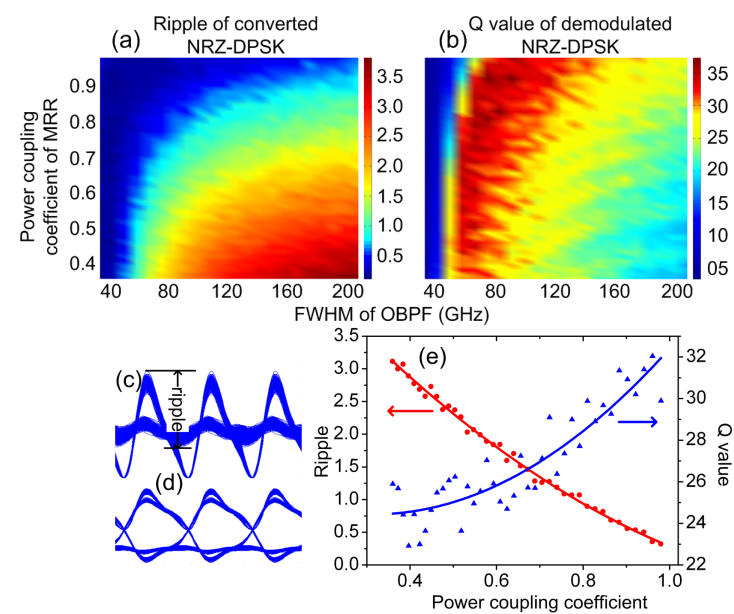

Fig. 1. (a) Amplitude ripple of the converted NRZ-DPSK and (b) Q value of the demodulated signal versus MRR power coupling and OBPF 3 -dB bandwidth at $41.6 \mathrm{~Gb} / \mathrm{s}$. Eye diagrams of (c) converted NRZDPSK and (d) demodulated signal after balanced detection. (e) Ripple and $Q$ value versus MRR power coupling coefficient for $1 \mathrm{~nm} \mathrm{OBPF}$.

\section{DEVICE FABRICATION AND EXPERIMENTAL RESULTS}

The MRR was fabricated on a SOI wafer with top silicon thickness of $250 \mathrm{~nm}$ and buried silica of $3 \mu \mathrm{m}$. Fig. 2(a) to (c) show the structure of the device. The radius of the MRR is $147 \mu \mathrm{m}$ with waveguide width of $470 \mathrm{~nm}$ and coupling gap of $100 \mathrm{~nm}$. To decrease the device insertion loss, a silicon nano taper, depicted in Fig. 2(c), was adopted. Fig. 2(d) shows the measured transmission spectrum of the MRR. Low insertion loss of 
$8 \mathrm{~dB}$ is achieved with an FSR of $83 \mathrm{GHz}$ and an extinction ratio (ER) of $25 \mathrm{~dB}$, which corresponds to a power coupling coefficient of 0.9 , as designed.

Fig. 3 shows the experimental setup for format conversion. Continuous wave light at $1549.35 \mathrm{~nm}$ is modulated by two Mach-Zehnder modulators to generate a 33\% RZ-DPSK signal at $41.6 \mathrm{~Gb} / \mathrm{s}$. The pseudorandom binary sequence (PRBS) length is $2^{31}-1$. The signal is then amplified by an EDFA. Before being injected into the MRR, the polarization of the signal is adjusted to the TM mode with a polarization controller. The converted NRZ-DPSK signal after the MRR is filtered by an OBPF with $3-\mathrm{dB}$ bandwidth of $1 \mathrm{~nm}$ and finally detected by balanced detection in a preamplified receiver.

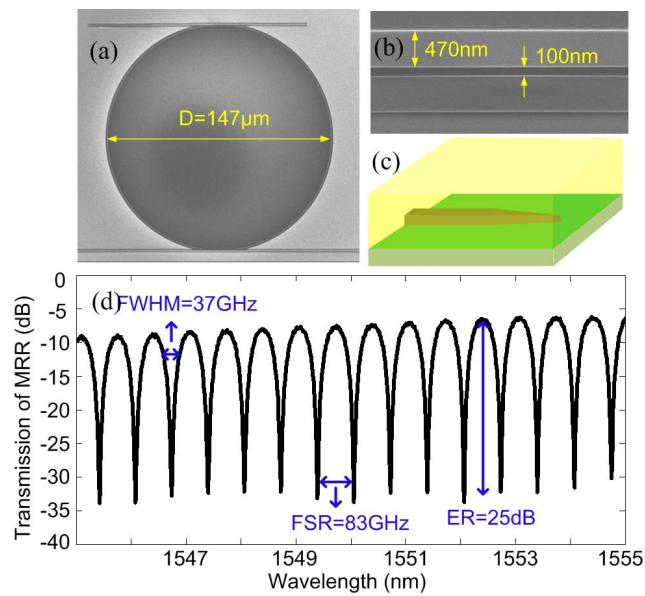

Fig. 2. Scanning electron microscope (SEM) pictures of (a) top view and (b) coupling region of the MRR. (c) Silicon nano taper. (d)

Measured transmission spectrum at the through port of the MRR.

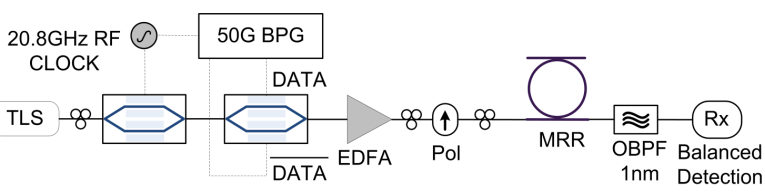

Fig. 3. Experimental setup for RZ-DPSK to NRZ-DPSK conversion.
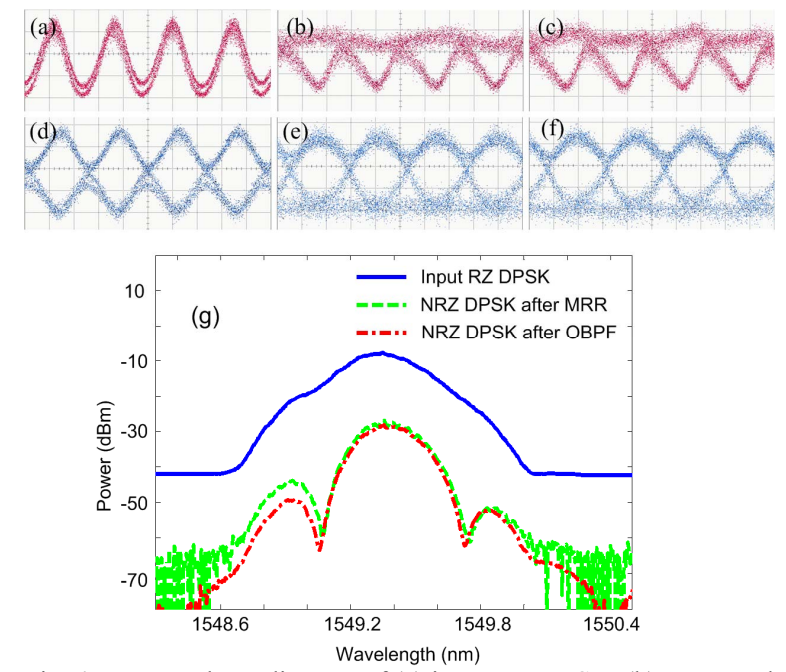

Fig. 4. Measured eye diagram of (a) input RZ-DPSK, (b) converted NRZ-DPSK after MRR, (c) converted NRZ-DPSK after OBPF and (d) to (f) their corresponding demodulated signals for balanced detection. (g) Spectra of the input RZ-DPSK, NRZ-DPSK after MRR and NRZ-DPSK after OBPF (resolution bandwidth: $0.2 \mathrm{~nm}$ ).
Fig. 4(a) to (c) show the eye diagrams of the input RZDPSK, converted NRZ-DPSK after MRR and converted NRZ-DPSK after OBPF. The corresponding spectra and demodulated signals after balanced detection are also shown in Fig. 4(d) to (g). Since the bandwidth of the OBPF is relatively wide, the spectrum of the converted signal after the OBPF is not significantly modified compared with the one after MRR. However, thanks to the high MRR power coupling coefficient, low ripple in the converted NRZ-DPSK and high $Q$ value of the demodulated signal are obtained, as expected. Fig. 5 shows the BER measurements for format conversion. There is little power penalty during the conversion process.

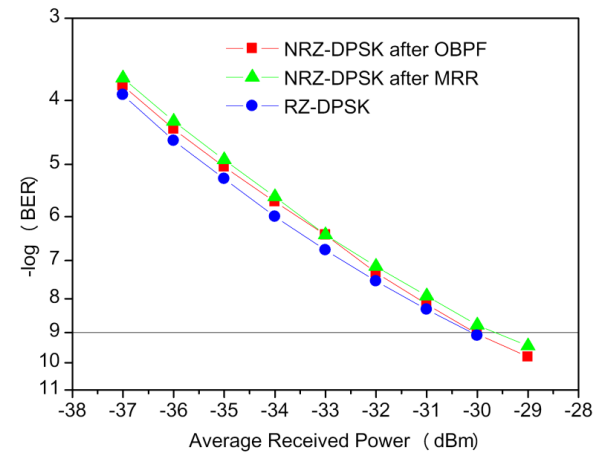

Fig. 5. BER measurements for input RZ-DPSK, converted NRZ-DPSK after MRR and converted NRZ-DPSK after OBPF.

\section{CONCLUSIONS}

RZ-DPSK to NRZ-DPSK format conversion at $41.6 \mathrm{~Gb} / \mathrm{s}$ has been demonstrated for the first time based on a well optimized custom-made silicon microring resonator. Little power penalty compared with the input RZ-DPSK signal is achieved in the BER measurements.

\section{REFERENCES}

[1] X. Lei, B. C. Wang, V. Baby, I. Glesk, and P. R. Prucnal, "All optical data format conversion between RZ and NRZ based on a Mach-Zehnder interferometric wavelength converter," IEEE Photon. Technol. Lett., vol. 15, pp. 308310, Feb. 2003.

[2] Y. Yu, X. L. Zhang, D. X. Huang, L. J. Li, and W. Fu, "20$\mathrm{Gb} / \mathrm{s}$ all-optical format conversions from RZ signals with different duty cycles to NRZ signals," IEEE Photon. Technol. Lett., vol. 19, pp. 1027-1029, July 2007.

[3] Y. Zhang, E. Xu, D. Huang, and X. Zhang, "All-optical format conversion from RZ to NRZ utilizing microfiber resonator," IEEE Photon. Technol. Lett., vol. 21, pp. 12021204, Sep. 2009.

[4] Y. Ding, C. Peucheret, M. Pu, B. Zsigri, J. Seoane, L. Liu, J. Xu, H. Ou, X. Zhang, and D. Huang, "Multi-channel WDM RZ-to-NRZ format conversion at $50 \mathrm{Gbit} / \mathrm{s}$ based on single silicon microring resonator," Opt. Express, vol. 18, pp. 21121-21130, Sep. 2010.

[5] P. Groumas, V. Katopodis, C. Kouloumentas, M. Bougioukos and H. Avramopoulos, "All-optical RZ-toNRZ conversion of advanced modulated signals," IEEE Photon. Technol. Lett., vol. 24, pp. 179-181, Feb. 2012.

[6] Z. Zhang, Y. Yu and X. Zhang, "Simultaneous all-optical demodulation and format conversion for multi-channel (CS)RZ-DPSK signals," Opt. Express, vol. 19, pp. 1242712433, Jun. 2011. 